\title{
Getuienis dat termoïnhibering en die opheffing daarvan deur suurstof plus kinetien by Great Lakes- slaaisaad verband hou met mitochondriale funksie
}

\author{
J.G.C. Small* \\ Fakulteit Natuurwetenskappe, Universiteit van die Oranje-Vrystaat, \\ Posbus 339, Bloemfontein, 9300 \\ E. Cronje \\ Departement Plantkunde en Genetika, Universiteit van die Oranje-Vrystaat, \\ Posbus 339, Bloemfontein, 9300
}

Ontwang 29 September 1995; aanvaar 3 Januarie 1996

\section{UITTREKSEL}

Termö̈nhibering van Lactuca sativa $L$. cv. Great Lakes 659 -saad het by $36^{\circ} \mathrm{C}$ voorgekom. Termö̈nhibering is deur ' $n$ kombinasie van $100 \% \mathrm{O}_{2}$ en kinetien ( $10 \mathrm{mg} \mathrm{dm^{-3 }}$ ) opgehef. Chlooramfenikol het die voordelige invloed van $\mathrm{O}_{2}$ plus kinetien opgehef.

Verskeie mitochondrionaktiwiteite (respirasie, koppeling, sekere matriksensiemaktiwiteite en inkorporering van $\left[{ }^{35} S\right]-$ metionien in mitochondrionproteïene) was by termogeïhibeerde saad laer as by saad wat by $25^{\circ} \mathrm{C}$ gelmbibeer is. Behandeling met suurstof plus kinetien het veroorsaak dat hierdie aktiwiteite by $36^{\circ} \mathrm{C}$ geimbibeerde saad tot dieselfde, of hoër vlakke plaasgevind het as by $25^{\circ} \mathrm{C}$-kontrolesaad.

Die profiel van $\left.{ }^{35} \mathrm{~S}\right]$-metioniengemerkte mitochondrionpolipeptiede van termogeïhibeerde saad het kwalitatief verskil van die van saad wat by $25^{\circ} \mathrm{C}$ geimbibeer is en saad wat by $36^{\circ} \mathrm{C}$ met $\mathrm{O}_{2}$ plus kinetien behandel is. Sade uit laasgenoemde twee behandelings het ' $n$ identiese profiel van $\left[{ }^{35} S\right]$-metioniengemerkte mitochondrionproteiene vertoon.

Die resultate van hierdie studie steun die hipotese dat die induksie en opheffing van termoühibering by slaaisaad onderskeidelik verband hou met verlaging en met stimulering van mitochondrionaktiwiteit/ontwikkeling.

\section{Abstract}

Evidence that thermoinhibition and the alleviation thereof by oxygen plus kinetin in Great Lakes lettuce seed is related to mitochondrial function

Thermoinhibition of Lactuca sativa $L c v$ Great Lakes 659 seeds occurred at $36^{\circ} C$. Thermoinhibition was alleviated by a combination of $100 \% \mathrm{O}_{2}$ and kinetin $\left(10 \mathrm{mg} \mathrm{dm^{-3 }}\right)$. Chloramphenicol nullified the effect of $\mathrm{O}_{2}$ plus kinetin.

A number of mitochondrial activities (respiration, coupling, certain matrix enzyme activities and incorporation of $\left[^{35} S\right]-$ methionine in mitochondrial proteins) were lower in thermoinhibited than in seeds imbibed at $25{ }^{\circ} \mathrm{C}$. Treating seeds with $O$, plus kinetin at $36^{\circ} \mathrm{C}$ restored these mitochondrial activities to the same or in some cases, to higher levels than in $25^{\circ} \mathrm{C}$ control seeds.

The profile of $\left[{ }^{35} \mathrm{~S}\right]$-methionine labelled mitochondrial polypeptides from thermoinhibited seeds differed qualitatively from that of seeds imbibed at $25^{\circ} \mathrm{C}$ and seeds treated with $\mathrm{O}_{2}$ plus kinetin at $36{ }^{\circ} \mathrm{C}$. The $\left[{ }^{35} \mathrm{~S}\right]$-methionine labelled protein profiles of seeds from the latter two treatments were identical.

The results of this study support the hypothesis that induction of thermoinhibition is related to reduction in mitochondrial function and that stimulation of mitochondrial activity/development could be causative in the alleviation of thermoinhibition.

\section{INLEIDING}

Die optimum temperatuur vir die ontkieming van slaaisaad is ongeveer $20^{\circ} \mathrm{C}$ maar verskille tussen kultivars kom voor. ${ }^{1,2}$ Ontkieming neem gewoonlik skerp af na die mate waarin die temperatuur bo die optimum verhoog word. In sommige kultivars soos Grand Rapids word ontkieming in die donker by laer temperature as in die lig gerem. ${ }^{3} \mathrm{By}$ 'n sekere hoë temperatuur egter word sowel lig as donkerontkieming totaal gerem. ${ }^{3}$ Hierdie verskynsel heet termoïnhibering. ${ }^{4}$

Die biochemiese meganisme van termoinhibering en die opheffing daarvan deur sekere behandelings is grootliks onbekend. ${ }^{5}$ Saini, et al. ${ }^{9}$ beweer dat etileensintese en -aksie benodig word vir die opheffmg van termoïnhibering. Small, et al., ${ }^{3}$ het die belangrikheid van etileen bevraagteken en aangetoon dat verhoogde ATP-vlakke moontlik verband hou met die opheffing van termoïnhibering. Laasgenoemde studie $^{3}$ wat met die donkersadige Grand Rapids-kultivar uitgevoer is, het aangetoon dat 'n kombinasie van $100 \%$ suurstof en kinetien 'n hoogs doeltreffende behandeling is om termoinhibering op te hef.

In die huidige studie word nagegaan of suurstof plus kinetien ook termoïnhibering van die witsadige Great Lakeskultivar kan ophef. $\mathrm{Na}$ aanleiding van die vorige bevinding ${ }^{3}$ dat 'n gebrek aan voldoende ATP-sintese moontlik met termoïnhibering verband hou en aangesien ATP-sintese primêr 'n mitochondriale funksie is, word die hipotese getoets dat die induksie en opheffing van termoïnhibering onder- 
skeidelik verband hou met verlaging en stimulering van mitochondrionaktiwiteit.

\section{EKSPERIMENTELE PROSEDURE}

\section{Materiaal}

Saad (strenggesproke dopvruggies) van Lactuca sativa $\mathrm{L}$. cv Great Lakes 659 is vanaf die Sensako saadmaatskappy verkry en in lugdigte glasbottels in die donker by $2^{\circ} \mathrm{C}$ geberg.

Panacide (5,5'-2, 2'-dihidroksie difenielmetaan) is van BDH Chemicals, Poole, VK aangekoop. Chlooramfenikol, kinetien en gibberelliensuur $\left(\mathrm{GA}_{3}\right)$ is van Sigma Chemical Company, St. Louis, VSA verkry en vuurvlieglusiferien/ lusiferase van Los Alamas, VSA. Proteïen molekulêre standaarde, Amplify, Hyperfilm-MP en $\left[{ }^{35} \mathrm{~S}\right]$-metionien is van Amersham International, VK verkry. Ander biochemikalieë is van Boehringer-Mannheim, Duitsland, verkry.

Medies suiwergraad gasse $\left(\mathrm{O}_{2}, \mathrm{CO}_{2}\right.$, etileen $)$ is deur Fedgas, Suid-Afrika verskaf.

Kinetien is in $0,5 \mathrm{~mol} \mathrm{dm}^{-3} \mathrm{HCL}$ opgelos en daarna met $\mathrm{NaOH}$ geneutraliseer.' Chlooramfenikol en $\mathrm{GA}_{3}$ is eers in ' $\mathrm{n}$ klein volume etanol opgelos en na verdunning met gedistilleerde water is die etanol afgedamp tot 'n konsentrasie van minder as $1 \mathrm{mmol} \mathrm{dm}^{-3}$. Hierdie konsentrasie etanol het nie ontkieming beïnloed nie.

\section{Ontkieming}

Sade is vooraf vir $2 \mathrm{~min}$. in $0,5 \%(\mathrm{~m} / \mathrm{v})$ waterige Panacide gesteriliseer en daarna met groot volumes steriele gedistilleerde water afgespoel. Vyf-en-twintig sade is op 'n enkellaag-filtreerpapier wat met toetsoplossing (water; kinetien, $10 \mathrm{mg} \mathrm{dm}^{-3}$; chlooramfenikol, $10 \mathrm{mmol} \mathrm{dm}^{-3}$; of $\mathrm{GA}_{3}, 100$ $\mathrm{mg} \mathrm{dm}^{-3}$ ) benat is, in $55 \mathrm{~mm}$ deursnee plastiek Petri-bakkies geïnkubeer. Petri-bakkies met sade is in $2,2 \mathrm{dm}^{3}$ deursigtige plastiekbottels met gasdigte deksels geplaas. 'n Rubberseptum is in die deksel aangebring waardeur $\mathrm{O}_{2}(100 \%), \mathrm{CO}_{2}$ $(10 \% \mathrm{v} / \mathrm{v})$ of etileen $\left(100 \mathrm{~mm}^{3} \mathrm{dm}^{-3}\right)$ in die bottel ingelaat is. Vir die $100 \%-0_{2}$-behandeling is hierdie gas teen $600 \mathrm{~cm}^{3} \mathrm{~min}$. ${ }^{1}$ deur die bottel vir 30 min. geborrel waarna die bottel verseël is. Die resultate wat met hierdie behandeling verkry is, was dieselfde as waar $100 \% 0_{2}$ kontinu vir die duurte van die eksperiment deur die bottel geborrel is.

Sade is by $25 \pm 0,2^{\circ} \mathrm{C}$ en $36 \pm 0,2^{\circ} \mathrm{C}$ in witlig ("coolwhite" buislig, $16 \mathrm{~mol} \mathrm{~m}^{-2} \mathrm{~s}^{-1}$ ) geïnkubeer en is as ontkiem beskou wanneer die radikula verskyn het.

Konsentrasies van toetsoplossings en gasse wat in eksperimente gebruik is, is in voorafeksperimente as optimaal bepaal.

\section{Suurstofopname}

Suurstofopname van sade is polarografies by $25^{\circ} \mathrm{C}$ met ' $\mathrm{n}$ Clark-elektrode (Yellow Springs Instrument Company, Yellow-Springs, Ohio) bepaal. Die reaksiekuvet het $3 \mathrm{~cm}^{3}$ water en 25 ontkiemde of 50 onontkiemde sade bevat.

\section{ATP}

Die metodes vir prosessering van weefsel en bepaling van adeniennukleotiede deur middel van die lusiferien/lusiferase tegniek, is soos beskryf deur Raymond en Pradet. ${ }^{6}$

\section{Ekstrahering en bepaling van etanol}

Sade (100) is op filtreerpapier wat met toetsoplossing benat is, in $100 \mathrm{~cm}^{3}$ Schott Duran glasreagensbottels geinkubeer. Bottels is met behulp van rubberseptums verseël. 'n $100 \%$ $0_{2}$-atmosfeer is verkry deur bottels aan die begin van 'n eksperiment vir $30 \mathrm{~min}$. $\left(600 \mathrm{~cm}^{3} \mathrm{~min}^{-1}\right)$ met $0_{2}$ te spoel.

$\mathrm{Na} 24$ uur is etanol geëkstraheer en bepaal soos reeds beskryf.?

\section{Isolering en suiwering van mitochondrions}

Gewaste mitochondrions is uit heel sade berei soos beskryf deur Morohashi, et al. ${ }^{8}$ Gewaste mitochondrions is verder op 'n selfgenererende Percoll-gradient gesuiwer. ${ }^{9}$ Gesuiwerde mitochondrions was $93 \pm 3 \%$ intak.

\section{Suurstofopname van mitochondrions}

Dit is polarografies met 'n Hansatech Clark-elektrode by $25{ }^{\circ} \mathrm{C}$ bepaal. Die reaksiekuvet $\left(1 \mathrm{~cm}^{3}\right)$ het $25 \mathrm{mmol} \mathrm{dm}^{-3}$ HEPES (N-(2-hidroksittiel) piperasien-N-2-etaansulfoonsuur) (pH 7,2), $5 \mathrm{mmol} \mathrm{dm}^{-3} \mathrm{~K}-\mathrm{Pi}$ (kaliumfosfaatbuffer) (pH 7,2), $0,4 \mathrm{mmol} \mathrm{dm}^{-3}$ mannitol, $5 \mathrm{mmol} \mathrm{dm}{ }^{-3} \mathrm{MgCl}_{2}$ en $0,1 \%$ $(\mathrm{m} / \mathrm{v})$ BSA (beesserumalbumien) bevat. Suksinaat ( $10 \mathrm{mmol}$ $\mathrm{dm}^{-3}$ plus $0,6 \mathrm{mmol} \mathrm{dm}^{-3}$ ATP), NADH (nikotienamiedadenien dinukleotied gereduseerd $10 \mathrm{mmol} \mathrm{dm}^{-3}$ ) en malaat (7 $\mathrm{mmol} \mathrm{dm}^{-3}$ plus $0,3 \mathrm{mmol} \mathrm{dm^{-3 }}$ ATP) is as respiratoriese substrate gebruik. ADP/O-verhoudings is bepaal na byvoeging van $24 \mathrm{nmol} A \mathrm{AP}$.

\section{Mitochondriale ensiemaktiwiteite}

Gesuiwerde mitochondrions is vir aktiwiteitsbepalings van ensieme gebruik. Vir elke ensiem is reagens- en mitochondrionkonsentrasies in voorafeksperimente geoptimiseer.

\section{$\alpha$-Ketoglutaarsuurdehidrogenase ( $\alpha-K G D H)$}

Die aktiwiteit is by $340 \mathrm{~nm}$ bepaal deur die vorming van NADH. ${ }^{10}$ Die reaksiemedium van $1 \mathrm{~cm}^{3}$ het bevat $20 \mathrm{mmol}$ $\mathrm{dm}^{-3}$ HEPES ( $\mathrm{pH} \mathrm{7.0),8} \mathrm{mmol} \mathrm{dm}^{-3} \mathrm{MgCl}_{2}, 20 \mathrm{mmol} \mathrm{dm}^{-3}$ DTT (ditiotreitol), $2,8 \mathrm{mmol} \mathrm{dm}^{-3} \mathrm{NAD}^{+}, 4 \mathrm{~mol} \mathrm{dm}^{-3}$ antimisien $\mathrm{A}, 0,23 \mathrm{mmol} \mathrm{dm}^{-3}$ TPP (tiamienpirofosfaat), $2 \mathrm{mmol} \mathrm{dm}{ }^{-3} \mathrm{ADP}, 10 \mathrm{mmol} \mathrm{dm}^{-3} \mathrm{~K}-\mathrm{Pi}(\mathrm{pH} 7,0), 20 \mu \mathrm{mol} \mathrm{dm}$ ${ }^{3} \mathrm{CoA}$ (koënsiem-A) en gesuiwerde mitochondrions. Die reaksie is met $9 \mathrm{mmol} \mathrm{dm}^{-3} \alpha$-ketogluraat begin.

\section{Appelsuurensiem (ME)}

Die NAD ${ }^{+}$-afhanklike ME-aktiwiteit van mitochondrions is bepaal deur die reduksie van $\mathrm{NAD}^{+}$by $340 \mathrm{~nm}$ in die volgende medium te meet: $80 \mathrm{mmol} \mathrm{dm}^{3} \mathrm{~K}-\mathrm{Pi}(\mathrm{pH} 6,8), 30 \mathrm{mmol} \mathrm{dm}^{-3}$ malaat, $0,5 \mathrm{mmol} \mathrm{dm}^{-3} \mathrm{NAD}^{+}$en $1 \mathrm{mmol} \mathrm{dm}^{-3} \mathrm{MnCl}_{2}$. Die reaksie is geînisieer deur byvoeging van $\mathrm{MnCl}_{2}$, 'n obligate kofaktor vir ME-aktiwiteit," en $0,4 \%$ (v/v) Triton X-100. Verder is 0,5 mmol $\mathrm{dm}^{-3} \mathrm{KCN}$ en $1 \mathrm{mmol} \mathrm{dm}{ }^{-3}$ SHAM (salisielhidroksaamsuur) bygevoeg om elektronvloei na $\mathrm{O}_{2}$ te rem.

\section{Malaatdehidrogenase ( $M D H)$}

Die aktiwiteit is bepaal deur die oksidasie van NADH by $340 \mathrm{~nm}$ te volg. ${ }^{12}$ Die reaksie-medium het die volgende bevat: $80 \mathrm{mmol} \mathrm{dm}^{-3} \mathrm{~K}$-Pi (pH 7,5), 3,75 mmol dm $\mathrm{mgCl}_{2}, 23$ mmol dm${ }^{-3}$ oksaalasetaat en $0,25 \mathrm{mmol} \mathrm{dm}^{-3} \mathrm{NADH}$.

\section{Suksinaatdehidrogenase (SDH)}

Die aktiwiteit is bepaal deur die reduksie van DCPIP (dichlorofenolindofenol) by $600 \mathrm{~nm}^{13}$ in die volgende reaksiemedium te volg: $80 \mathrm{mmol} \mathrm{dm}^{-3} \mathrm{~K}-\mathrm{Pi}(\mathrm{pH} 7,5), 0,8$ mmol dm ${ }^{-3}$ PMS (fenasienmetosulfaat), $1 \mathrm{mmol} \mathrm{dm}^{-3} \mathrm{KCN}$, $96 \mu \mathrm{mol} \mathrm{dm}{ }^{-3}$ DCPIP en $5 \mu \mathrm{mol} \mathrm{dm}{ }^{-3}$ ATP. Die reaksie is begin deur byvoeging van $40 \mathrm{mmol} \mathrm{dm}^{-3}$ suksinaat.

'n Waarde van $16.1 \times 10^{3} \mathrm{dm}^{3} \mathrm{~mol}^{-1} \mathrm{~cm}^{-1}$ is vir die molare absorbeervermoë van DCPIP geneem. ${ }^{13}$

\section{Sitochroomoksidase ( $\mathrm{CO})$}

Sitochroomoksidase se aktiwiteit is bepaal deur die afname in absorbansie by $550 \mathrm{~nm}$ te volg tydens die oksidasie van gereduseerde sitochroom-C. Die reaksiemedium het $70 \mathrm{mmol}$ $\mathrm{dm}^{-3} \mathrm{~K}-\mathrm{Pi}(\mathrm{pH} 7,4)$ en $15 \mu \mathrm{mol} \mathrm{dm}{ }^{-3}$ gereduseerde sitochroom$\mathrm{C}$ bevat.

Die gereduseerde sitochroom-C is soos volg berei: $0,1 \mathrm{mmol}$ $\mathrm{dm}^{-3}$ sitochroom-C is in $20 \mathrm{mmol} \mathrm{dm}{ }^{-3} \mathrm{~K}-\mathrm{Pi}(\mathrm{pH} \mathrm{7,4)}$ opgelos 
en met $40 \mathrm{~mm}^{3} 1.2 \mathrm{~mol} \mathrm{dm}^{-3} \mathrm{Na}_{2} \mathrm{~S}_{2} \mathrm{O}_{4}$ gereduseer. Hierna is lug deur die oplossing geborrel om oortollige $\mathrm{Na}_{2} \mathrm{~S}_{2} \mathrm{O}_{4}$ te oksideer. 'n Waarde van $21.1 \times 10^{3} \mathrm{dm}^{3} \mathrm{~mol}^{-1} \mathrm{~cm}^{-1}$ is as die molare absorbeervermoë van sitochroom-C geneem. ${ }^{14}$

\section{Piruvaatdehidrogenasekompleks (PDH)}

Die metode van Dry \& Wiskich" is gebruik. Die ensiemkompleks is geaktivecr deur die mitochondrionsuspensie vir $0,5 \mathrm{~h}$ by $4^{\circ} \mathrm{C}$ in die volgende medium te inkubeer: $100 \mathrm{mmol} \mathrm{dm}^{-3}$ Tris-HCL (Tris(hidroksiemetiel) aminometaan) (pH 7,5), 40 mmol dm ${ }^{3} \mathrm{Mg} \mathrm{Cl}_{2}$ en $0,2 \%$ (v/v) Triton X-100. Die mengsel is vir $20 \mathrm{~min}$. by $27000 \times \mathrm{g}$ gesentrifugeer en die supernatant is vir aktiwiteitsbepaling gebruik. Die reaksiemengsel het die volgende bevat: $25 \mathrm{mmol} \mathrm{dm}^{-3}$ TES (N-tris(hidroksie-

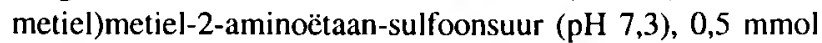
$\mathrm{dm}^{-3} \mathrm{TPP}, 1 \mathrm{mmol} \mathrm{dm}{ }^{-3} \mathrm{MgCl}_{2}, 1 \mathrm{mmol} \mathrm{dm}{ }^{-3} \mathrm{NAD}^{+}, 0,13 \mathrm{mmol}$

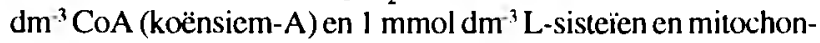
drionsuspensie. Hierdie medium is vir $1 \mathrm{~min}$. by $25^{\circ} \mathrm{C}$ geïnkubeer waarna $1 \mathrm{mmol} \mathrm{dm}^{3} \mathrm{Na}$-piruvaat bygevoeg is.

\section{Proteïenbepaling}

Proteïen is by $595 \mathrm{~nm}$ volgens die metode van Bradford ${ }^{15}$ bepaal. Bees-gammaglobulien is as verwysingstandaard gebruik.

\section{In vivo radioaktiewe merking van mitochondriale proteīene \\ Die metode van Spencer, et al., ${ }^{16}$ is gebruik.}

In alle gevalle is merking van saad met $\left[{ }^{35} \mathrm{~S}\right]$-metionien onder dieselfde toestande as met die ontkiemingsbehandelings uitgevoer. Merking het gedurende die eerste 10 uur van saadinkubering, dit wil sê voor ontkieming, plaasgevind. Tien sade is in $50 \mathrm{~mm}^{3}$-toetsoplossing bevattende $20 \mu \mathrm{Ci}\left[{ }^{35} \mathrm{~S}\right.$ - metionien ( $37 \mathrm{TBq}^{\mathrm{mmol}}{ }^{-1}$ ) geplaas en vir 5 sekondes geëvakueer.

$\mathrm{Na}$ inkubering van saad vir 10 uur is sade deeglik met gedistilleerde water gewas en drooggeklad. Mitochondrions is geisoleer en gesuiwer soos hierbo beskryf is.

Gesuiwerde mitochondrions is in $12,5 \mathrm{mmol} \mathrm{dm}^{-3}$ TrisHCL (pH 6,8), 10\% (v/v) gliserol, 2 mmol dm ${ }^{3}$ EDTA (cti-

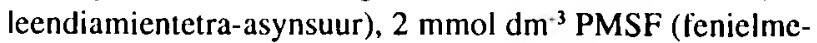
tielsulfonielfluoried), $14 \mathrm{mmol} \mathrm{dm}^{-3}$ B-merkaptoetanol en $2,3 \%(\mathrm{~m} / \mathrm{v})$ SDS (natrium dodesielsulfaat) gesuspendeer en vir $5 \mathrm{~min}$. by $95^{\circ} \mathrm{C}$ verhit.

Radioaktiwiteit van mitochondriale proteien is deur middel van vloeistofsintellasietelling gemeet. ${ }^{17}$

Poliakrielamiedjelelektroforese (PAGE) en fluorografie SDS-PAGE is volgens die metode van Laemmli ${ }^{18}$ uitgevoer

Jelle is met Coomassie-blou gekleur volgens Fish en Jagendorf. ${ }^{19} \mathrm{Na}$ ontkleuring is jelle met "Amplify" geimpregneer, gedroog en aan X-straalfilm (Hyperfilm-MP) by $-80^{\circ} \mathrm{C}$ blootgestel.

\section{RESULTATE}

\section{Saadontkieming}

Ontkieming in lug met water as imbiberingsmedium is volledig by $36^{\circ} \mathrm{C}$ gerem (termoinhibering) (tabel 1). Termoïnhibering in lug is in 'n groot mate deur ' $n$ kombinasic van hormone en $\mathrm{CO}_{2}$ opgehef. Afsonderlik was nie een van die faktore in staat om termoinhibering op te hef nic (tabe) 1). Termoïnhibering is volledig deur ' $n$ kombinasie van $\mathrm{O}_{2}$ en kinetien en effens minder doeltreffend deur $\mathrm{O}_{2}$ en etileen opgehef. ' $n$ Kombinasie van $\mathrm{O}_{2}$ en $\mathrm{GA}_{3}$ het nie termoinhibe-

\section{TABEL 1 Invloed van $\mathrm{O}_{2}$ en $\mathrm{CO}_{2}$ plus hormone en chlooramfenikol op ontkieming van Great Lakes 659- slaaisaad by $25^{\circ} \mathrm{C}$ en $36^{\circ} \mathrm{C}$ (gemiddeld \pm standaardfout, $n=3$ ). Die volgende konsentrasies is gebruik: kinetien (Kin) $10 \mathrm{mg} \mathrm{dm}^{-3}$, Gibberelliensuur $\left(\mathrm{GA}_{3}\right) 100 \mathrm{mg} \mathrm{dm}^{-3}$, etileen $(E) 100 \mathrm{~mm}^{3} \mathrm{dm}^{3}$, $\mathrm{CO}_{2}, 10 \%(\mathrm{v} / \mathrm{v}) ; \mathrm{O}_{2} 100 \%$ en chlooramfenikol (CA) $10 \mathrm{mmol} \mathrm{dm}^{-3}$}

\begin{tabular}{|c|c|c|c|c|}
\hline \multirow[t]{3}{*}{ Saadbehandeling } & \multirow{2}{*}{\multicolumn{4}{|c|}{$\%$ Ontkieming by }} \\
\hline & & & & \\
\hline & $24 \mathrm{~h}$ & $48 h$ & $24 \mathrm{~h}$ & $48 \mathrm{~h}$ \\
\hline $\begin{array}{l}\mathrm{Lug}+\mathrm{H}_{2} \mathrm{O} \\
\mathrm{Lug}+\mathrm{Kin} \\
\mathrm{Lug}+\mathrm{E} \\
\mathrm{Lug}+\mathrm{GA}_{3} \\
\text { Lug }+\mathrm{CA}^{2}\end{array}$ & $\begin{array}{l}96 \pm 0,2 \\
95 \pm 0,3 \\
94 \pm 0,2 \\
93 \pm 1 \\
75 \pm 1,2\end{array}$ & $\begin{array}{l}98 \pm 1 \\
97 \pm 0,4 \\
98 \pm 0,3 \\
96 \pm 2 \\
90 \pm 1\end{array}$ & $\begin{array}{l}0 \\
0 \\
0 \\
0 \\
0\end{array}$ & $\begin{array}{l}0 \\
1,33 \pm 3 \\
0 \\
0 \\
0\end{array}$ \\
\hline $\begin{array}{l}\mathrm{Lug}+\mathrm{Kin}+\mathrm{GA}_{3}+\mathrm{E}+\mathrm{CO}_{2} \\
\mathrm{Lug}+\mathrm{Kin}+\mathrm{GA}_{3}+\mathrm{E}+\mathrm{CO}_{2} \\
+\mathrm{CA}\end{array}$ & $\begin{array}{l}90 \pm 2 \\
93 \pm 0,4\end{array}$ & $\begin{array}{l}95 \pm 1,2 \\
94 \pm 1\end{array}$ & $\begin{array}{l}60 \pm 1,5 \\
0\end{array}$ & $\begin{array}{l}89 \pm 0.7 \\
0\end{array}$ \\
\hline $\begin{array}{l}\mathrm{O}_{2}+\mathrm{H}_{2} \mathrm{O} \\
\mathrm{O}_{2}+\mathrm{CA}^{2}\end{array}$ & $\begin{array}{l}96 \pm 0,5 \\
92 \pm 0,5\end{array}$ & $\begin{array}{l}98 \pm 0,5 \\
93 \pm 1\end{array}$ & $\begin{array}{l}0 \\
0\end{array}$ & $\begin{array}{l}0 \\
0\end{array}$ \\
\hline $\begin{array}{l}\mathrm{O}_{2}+\mathrm{Kin} \\
\mathrm{O}_{2}+\mathrm{Kin}+\mathrm{CA}\end{array}$ & $\begin{array}{l}97 \pm 0,6 \\
90 \pm 2\end{array}$ & $\begin{array}{l}98 \pm 0,7 \\
91 \pm 0,3\end{array}$ & $\begin{array}{l}93 \pm 0,3 \\
0\end{array}$ & $\begin{array}{l}94 \pm 0,3 \\
0\end{array}$ \\
\hline $\begin{array}{l}\mathrm{O}_{2}+\mathrm{E} \\
\mathrm{O}_{2}+\mathrm{E}+\mathrm{CA}\end{array}$ & $\begin{array}{l}91 \pm 0,3 \\
92 \pm 0,3\end{array}$ & $\begin{array}{l}92 \pm 0,2 \\
94 \pm 0,7\end{array}$ & $\begin{array}{l}43 \pm 5 \\
0\end{array}$ & $\begin{array}{l}90 \pm 1 \\
0\end{array}$ \\
\hline $\begin{array}{l}\mathrm{O}_{2}+\mathrm{GA}_{3} \\
\mathrm{O}_{2}+\mathrm{GA}_{3}+\mathrm{CA}\end{array}$ & $\begin{array}{l}92 \pm 0,1 \\
90 \pm 0,2\end{array}$ & $\begin{array}{l}95 \pm 0,3 \\
93 \pm 0,1\end{array}$ & $\begin{array}{l}0 \\
0\end{array}$ & $0^{3 \pm 1}$ \\
\hline $\begin{array}{l}\mathrm{O}_{2}+\mathrm{Kin}+\mathrm{E} \\
\mathrm{O}_{2}+\mathrm{Kin}+\mathrm{E}+\mathrm{CA}\end{array}$ & $\begin{array}{l}91 \pm 2 \\
90 \pm 0,3\end{array}$ & $\begin{array}{l}96 \pm 0,1 \\
93 \pm 1\end{array}$ & $\begin{array}{l}92 \pm 1 \\
1 \pm 0,3\end{array}$ & $\begin{array}{r}94 \pm 0,6 \\
3 \pm 0,5\end{array}$ \\
\hline
\end{tabular}


ring opgehef nie. Van die drie behandelings wat termoïnhibering opgehef het, was ' $\mathrm{n}$ kombinasie van $\mathrm{O}_{2}$ en kinetien die doeltreffendste aangesien 'n ontkiemingsyfer van meer as $93 \%$ reeds na 24 uur weens hierdie behandeling by $36^{\circ} \mathrm{C}$ verkry is.

Hierdie behandeling is dus in verdere studies gebruik.

Chlooramfenikol het die voordelige invloed van al drie die behandelings wat termoinhibering opgehef het, uitgewis. By $25^{\circ} \mathrm{C}$ in lug het chlooramfenikol ontkieming vertraag (tabel 1), maar was toenemend remmend met toename in temperatuur (tabel 2).

Aangesien chlooramfenikol 'n remmer van 70 S-ribosoom proteiensintese is ${ }^{20}$ en remming van ontkieming deur chooramfenikol hoofsaaklik by hoë temperatuur tot uiting gekom het, word gepostuleer dat die ontwikkeling van 'n organel deur hoë temperatuur gestrem word. Verder word gepostuleer dat 'n behandeling wat termoinhibering ophef voordelig vir organelontwikkeling is. Daar word voorgestel dat die remmende invloed van chlooramfenikol by hoë temperatuur te wyte is aan belemmering van organelontwikkeling.

Aangesien hoë temperatuur en chlooramfenikol respirasie onderdruk het (kyk later), word voorgestel dat die organel ter sprake mitochondrions is.

Bogenoemde hipotese is in die volgende eksperimente getoets. Weens die hoě koste van gespesialiseerde chemikalieë en om die ekstraksie van mitochondrions binne werkbare limiete te hou, is slegs sekere kardinale behandelings geselekteer.

Voor-ontkiemingsrespirasiekapasiteit, ATP, totale adenilate en adenilaatenergielading (AEC)

Om 'n aanduiding van respiratoriese vermoë te kry, is respirasie van saad wat by $25^{\circ} \mathrm{C}$ en $36^{\circ} \mathrm{C}$ geïnkubeer is by dieselfde temperatuur, naamlik $25^{\circ} \mathrm{C}$ gemeet. Die resultate in tabel 3 toon dat respirasiekapasiteit van saad wat by $36^{\circ} \mathrm{C}$ in water geïnkubeer is, laer was as die van die kontrolesaad by $25^{\circ} \mathrm{C}$. Behandeling van saad met $\mathrm{O}_{2}$ plus kinetien het ' $\mathrm{n}$ respirasiekapasiteit amper gelyk aan die van $25^{\circ} \mathrm{C}$ watergeïnkubeerde saad tot gevolg gehad. Chlooramfenikol het die respirasiekapasiteit verminder. Hierdie invloed van chlooramfenikol was groter by $36^{\circ} \mathrm{C}$ as by $25^{\circ} \mathrm{C}$ geïnkubeerde saad.

Hierdie remming deur chlooramfenikol was egter nie 'n direkte remming van respirasie nie aangesien byvoeging van chlooramfenikol tydens respirasiemeting van voorafwatergemkubeerde saad nie respirasie gerem het nie (resultate nie getoon).

Suurstof plus kinetienbehandeling van saad by $36^{\circ} \mathrm{C}$ het 'n noemenswaardige toename in die ATP-vlak van saad na $10 \mathrm{~h}$ tot gevolg gehad, terwyl die vlakke in saad van al die ander behandelings soortgelyk was.

Die totale adenilaatvlak was ook hoër in saad wat met $\mathrm{O}_{2}$ plus kinetien behandel is, terwyl die tweede hoogste vlak in die $25^{\circ} \mathrm{C}$-waterkontrolesaad voorgekom het.

Die energielading in saad uit al die behandelings, behalwe die hoë temperatuur chlooramfenikol behandeling, was hoog. By $36^{\circ} \mathrm{C}$ het chlooramfenikol 'n merkbare verlaging in AEC tot gevolg gehad.

\section{Etanolproduksie}

Die totale etanolproduksie van sade oor ' $\mathrm{n} 24 \mathrm{~h}$-periode word in tabel 4 getoon. Sade wat by $36^{\circ} \mathrm{C}$ in water geïnkubeer is, het merkbaar gefermenteer, terwyl sade by dieselfde temperatuur wat met $\mathrm{O}_{2}$ plus kinetien behandel is bykans geen fermentasie getoon het nie. By $25^{\circ} \mathrm{C}$ is klein hoeveelhede etanol gevorm wat op geringe fermentasie dui.

\section{Mitochondrionaktiwiteit}

Die resultate in tabel 5 toon dat hoëtemperatuur-inkubering van saad die respiratoriese kapasiteit van geîsoleerde mitochondrions merkbaar met al drie substrate verlaag het. Suurstof plus kinetienbehandeling van saad het hierdie invloed opgehef en tot gevolg gehad dat die respiratoriese kapasiteit van mitochondrions soortgelyk was aan die van saad wat by $25^{\circ} \mathrm{C}$ (water) geïmbibeer is. Chlooramfenikol-

TABEL 2 Invloed van chlooramfenikol (10 $\left.\mathrm{mmol} \mathrm{dm}^{-3}\right)$ op ontkieming van Great Lakes 659-slaaisaad by verskillende temperature in die lig

\begin{tabular}{|c|c|c|c|c|c|}
\hline \multirow{2}{*}{$\begin{array}{l}\text { Saad- } \\
\text { behandeling }\end{array}$} & \multirow{2}{*}{$\begin{array}{l}\text { Inkuberings- } \\
\text { tyd }\end{array}$} & \multicolumn{4}{|c|}{ Temperatuur } \\
\hline & & $25^{\circ} \mathrm{C}$ & $27^{\circ} \mathrm{C}$ & $30^{\circ} \mathrm{C}$ & $32^{\circ} \mathrm{C}$ \\
\hline Water & $\begin{array}{l}24 h \\
48 h\end{array}$ & $\begin{array}{l}96 \pm 4 \\
96 \pm 4\end{array}$ & $\begin{array}{l}90 \pm 2 \\
94 \pm 2\end{array}$ & $\begin{array}{l}86 \pm 10 \\
90 \pm 10\end{array}$ & $\begin{array}{l}80 \pm 4 \\
84 \pm 4\end{array}$ \\
\hline Chlooramfenikol & $\begin{array}{l}24 h \\
48 h\end{array}$ & $\begin{array}{l}75 \pm 4 \\
92 \pm 4\end{array}$ & $\begin{array}{l}66 \pm 2 \\
78 \pm 2\end{array}$ & $\begin{array}{l}16 \pm 1 \\
40 \pm 8\end{array}$ & $\begin{array}{l}0 \\
34 \pm 2\end{array}$ \\
\hline
\end{tabular}

TABEL 3 Voorontkiemings- respiratoriese kapasiteit, ATP, totale adenilaatinhoud en adenilaatenergielading (AEC) van Great Lakes 659-slaaisaad wat by $25^{\circ} \mathrm{C}$ en $36^{\circ} \mathrm{C}$ vir $10 \mathrm{~h}$ geïmbibeer is. (Konsentrasies soos in tabel 1)

\begin{tabular}{|l|l|l|l|l|}
\hline $\begin{array}{l}\text { Saad- } \\
\text { behandeling } \\
\text { vir } 10 \mathrm{~h}\end{array}$ & $\begin{array}{l}\mathrm{O}_{2} \text {-opname } \\
\text { by 25 } \\
\text { (nmol } \mathrm{C} \\
\mathrm{min}^{-1} \text { ) }\end{array}$ & $\begin{array}{l}\text { ATP } \\
\text { nmol } \\
\text { saad' }\end{array}$ & $\begin{array}{l}\text { Totale } \\
\text { adenilate } \\
\text { (nmol saad }\end{array}$ & AEC \\
\hline $25^{\circ} \mathrm{C}$-lug $+\mathrm{H}_{2} \mathrm{O}$ & $273 \pm 15$ & $0,284 \pm 0,01$ & $0,690 \pm 0,03$ & $0,80 \pm 0,1$ \\
$25^{\circ} \mathrm{C}$-lug $+\mathrm{CA}$ & $189 \pm 6$ & $0,25 \pm 0,04$ & $0,80 \pm 0,1$ \\
$36^{\circ} \mathrm{C}$-lug $+\mathrm{H}_{2} \mathrm{O}$ & $167 \pm 15$ & $0,28 \pm 0,03$ & $0,354 \pm 0,03$ & $0,82 \pm 0,10$ \\
$36^{\circ} \mathrm{C}-\mathrm{O}_{2}+\mathrm{Kin}$ & $256 \pm 16$ & $0,641 \pm 0,16$ & $0,377 \pm 0,04$ & $0,74 \pm 0,11$ \\
$36^{\circ} \mathrm{C}-\mathrm{O}_{2}+\mathrm{Kin}+\mathrm{CA}$ & $111 \pm 8$ & $0,245 \pm 0,01$ & $0,520 \pm 0,04$ & $0,58 \pm 0,04$ \\
\hline
\end{tabular}


behandeling van saad het die respiratoriese kapasitcit van mitociondrions verlaag.

Die ADP:O-verhoudings van mitochondrions toon dat hoëtemperatuur-inkubering van saad in water mitochondrions ontkoppel het (tabel 6). Suurstof plus kinetienbehandeling het koppeling herstel, maar chlooramfenikol het hierdie invloed opgehef. By $25^{\circ} \mathrm{C}$ het chlooramfenikol slegs ontkoppeling van malaatgedrewe elektronvloei teweeggebring, terwyl met NADH en suksinaat as substrate 'n

\begin{tabular}{|c|c|}
\hline TABEL 4 & $\begin{array}{l}\text { Invloed van } \mathrm{O}_{3} \text { plus kinetien en } \\
\text { chlooramfenikol op totale etanolpro- } \\
\text { duksie van Great Lakes } 659-\text { slaai- } \\
\text { saad na } 24 \mathrm{~h} \text { inkubering by } 25^{\circ} \mathrm{C} \text { en } \\
36^{\circ} \mathbf{C}\end{array}$ \\
\hline \multicolumn{2}{|c|}{} \\
\hline Saadbehandeling & $\begin{array}{c}\text { Totale etanolproduksie } \\
\left(\mu \mathrm{g} 100^{-1} \text { sade na } 24 \mathrm{~h}\right)\end{array}$ \\
\hline $25^{\circ} \mathrm{C}-$ lug $+\mathrm{H}_{2} \mathrm{O}$ & $5,67 \pm 2$ \\
$25^{\circ} \mathrm{C}-$ lug $+\mathrm{CA}^{\circ}$ & $5,74 \pm 1,3$ \\
$36^{\circ} \mathrm{C}-$ lug $+\mathrm{H}_{2} \mathrm{O}$ & $17,96 \pm 2,5$ \\
$36^{\circ} \mathrm{C}-\mathrm{O}_{2}+\mathrm{Kin}$ & $1,66 \pm 0,2$ \\
$36^{\circ} \mathrm{C}-\mathrm{O}_{2}+\mathrm{Kin}+\mathrm{CA}$ & $1,10 \pm 0,2$ \\
\hline
\end{tabular}

verlaging in ADP:O-verhoudings waargeneem is.

Wat mitochondriale ensieme betref (tabel 7), is die membraangebonde sitochroomoksidaseaktiwiteit nie deur hoẻ temperatuur of chlooramfenikol beìnvloed nie. Die matriksensieme $\alpha-\mathrm{KGDH}, \mathrm{MDH}, \mathrm{PDH}$ en $\mathrm{ME}$ se aktiwiteite is deur hoê temperatuur verlaag en in die geval van $\mathrm{MDH}$ en ME is aktiwiteite deur suurstof plus kinetien by hoë temperatuur herstel tot lae temperatuurvlakke. Chlooramfenikol het verlaging in vlakke van $\mathrm{SDH}, \alpha-\mathrm{KGDH}$ (slegs by hoë temperatuur) en ME tot gevolg gehad.

\section{Proteïensintese}

Inkorporering van $\left[{ }^{35} \mathrm{~S}\right]$-metionien in proteïene wat na 10 uur van saadinkubering in mitochondrions voorgekom het, is merkbaar deur hoë temperatuur verlaag (tabel 8). Suurstof plus kinetienbehandeling het proteiensintese by $36^{\circ} \mathrm{C}$ volkome en tot selfs ' $n$ hoër vlak as in die waterkontrole by $25^{\circ} \mathrm{C}$ laat herstel. Chlooramfenikol het inkorporering van $\left[{ }^{35} \mathrm{~S}\right]$-metionien in mitochondriale proteïene betekenisvol gerem.

Hierdie kwantitatiewe asook kwalitatiewe verskille van mitochondrionproteiene is duidelik sigbaar in ' $n$ fluorogram van geëkstraheerde proteiene (figuur 1). Die remmende invloed van chlooramfenikol op inkorporering van [ $\left.{ }^{35} \mathrm{~S}\right]-$

\section{TABEL 5 Staat $3 \mathrm{O}_{2}$-opnamekapasiteit van geisoleerde gesuiwerde mitochondrions van Great Lakes 659-slaaisaad wat by $25{ }^{\circ} \mathrm{C}$ en $36{ }^{\circ} \mathrm{C}$ vir $10 \mathrm{~h}$ geïmbibeer is. Die volgende respiratoriese substrate is gebruik NADH $\left(10 \mathrm{mmol} \mathrm{dm}^{-3}\right)$, suksinaat $\left(10 \mathrm{mmol} \mathrm{dm}^{-3}+0,6 \mathrm{mmol} \mathrm{dm}^{-3}\right.$ ATP) en malaat (7 mmol dm $\left.\mathrm{mm}^{-3}+0,3 \mathrm{mmol} \mathrm{dm}^{-3} \mathrm{ATP}\right)$. Suurstofopname uitgedruk as $\mathrm{nmol} \mathrm{O}_{2} \mathrm{mg}^{-1}$ proteïen $\mathrm{min}^{-1}$. Konsentrasies van Kin, $\mathrm{O}_{2}$ en CA soos in tabel 1}

\begin{tabular}{|l|l|c|c|}
\hline \multirow{2}{*}{ Saadbehandeling } & \multicolumn{3}{|c|}{$\mathrm{O}_{2}$-opname met substrate } \\
\cline { 2 - 4 } & $\mathrm{NADH}$ & Suksinaat & Malaal \\
\hline $25^{\circ} \mathrm{C}$-lug $+\mathrm{H}_{2} \mathrm{O}$ & $43,9 \pm 5$ & $30,2 \pm 3$ & $21,8 \pm 1,5$ \\
$25^{\circ} \mathrm{C}$-lug $+\mathrm{CA}$ & $29,9 \pm 0,2$ & $21,8 \pm 1$ & $14,4 \pm 4$ \\
$\%$ inhibering deur CA & 31,9 & 27,8 & 33,9 \\
$36^{\circ} \mathrm{C}$-lug $+\mathrm{H}_{2} \mathrm{O}$ & $21,8 \pm 1$ & $16,9 \pm 1,9$ & $16,9 \pm 1$ \\
$36^{\circ} \mathrm{C}-\mathrm{O}_{2}+\mathrm{Kin}$ & $43,2 \pm 2$ & $27,5 \pm 0,2$ & $19,3 \pm 0,9$ \\
$36^{\circ} \mathrm{C}-\mathrm{O}_{2}+$ Kin $+\mathrm{CA}$ & $20,3 \pm 5$ & $16,9 \pm 1,4$ & $14,3 \pm 2,4$ \\
$\%$ inhibering deur CA & 52,8 & 38,4 & 26,0 \\
\hline
\end{tabular}

TABEL 6 ADP/O-verhoudings van geïsoleerde gesuiwerde mitochondrions van saad wat by $25^{\circ} \mathrm{C}$ en $36^{\circ} \mathrm{C}$ vir $10 \mathrm{~h}$ geïmbibeer is. Konsentrasies van substrate, $\mathrm{Kin}, \mathrm{O}_{2}$ en $\mathrm{CA}$ soos in tabel 5

\begin{tabular}{|l|l|l|l|}
\hline Saadbehandeling & NADH & Suksinaat & Malaat \\
\hline $25^{\circ} \mathrm{C}$-lug $+\mathrm{H}_{2} \mathrm{O}$ & $1,19 \pm 0,36$ & $1,33 \pm 0,4$ & $0,95 \pm 0,33$ \\
$25^{\circ} \mathrm{C}-$ lug $+\mathrm{CA}$ & $0,99 \pm 0,21$ & $1,17 \pm 0,33$ & Geen \\
$36^{\circ} \mathrm{C}-$ lug $+\mathrm{H}_{2} \mathrm{O}$ & Geen & Geen & Geen \\
$36^{\circ} \mathrm{C}-\mathrm{O}_{2}+\mathrm{Kin}$ & $0,82 \pm 0,3$ & $0,9 \pm 0,1$ & $0,99 \pm 0,09$ \\
$36^{\circ} \mathrm{C}-\mathrm{O}_{2}+\mathrm{Kin}+\mathrm{CA}$ & Geen & Geen & Geen \\
\hline
\end{tabular}

TABEL 7 Mitochondriale ensiemaktiwiteite van saad wat by $25^{\circ} \mathrm{C}$ en $36{ }^{\circ} \mathrm{C}$ vir $10 \mathrm{~h}$ geimbibeer is. Konsentrasies van Kin, $\mathrm{O}_{2}$ en CA soos in tabel 1. Eenhede vir SDH, $\alpha-\mathrm{KGDH}, \mathrm{PDH}, \mathrm{ME}$ en

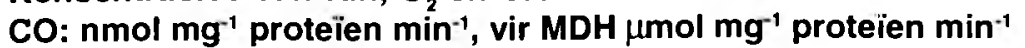

\begin{tabular}{|l|l|c|c|c|c|c|}
\hline Saadbehandeling & SDH & $\alpha-\mathrm{KGDH}$ & $\mathrm{MDH}$ & PDH & ME & $\mathrm{CO}$ \\
\hline $25^{\circ} \mathrm{C}$-lug $+\mathrm{H}_{2} \mathrm{O}$ & $60,2 \pm 6$ & $18,3 \pm 3$ & $8,1 \pm 1,8$ & $17,7 \pm 10$ & $92,9 \pm 33$ & $274 \pm 6$ \\
$25^{\circ} \mathrm{C}-$ lug $+\mathrm{CA}$ & $37,0 \pm 5$ & $29,9 \pm 7$ & $6,1 \pm 0,1$ & $16,7 \pm 2$ & $53,9 \pm 2$ & $261 \pm 23$ \\
$36^{\circ} \mathrm{C}-$ lug $+\mathrm{H}_{2} \mathrm{O}$ & $67,4 \pm 3$ & $13,9 \pm 0,4$ & $4,7 \pm 0,4$ & $4,3 \pm 1,6$ & $37,0 \pm 2$ & $263 \pm 10$ \\
$36^{\circ} \mathrm{C}-\mathrm{O}_{2}+\mathrm{Kin}$ & $60,1 \pm 5$ & $14,2 \pm 0,9$ & $11,1 \pm 0,9$ & $4,0 \pm 0,5$ & $92,3 \pm 5$ & $273 \pm 5$ \\
$36^{\circ} \mathrm{C}-\mathrm{O}_{2}+\mathrm{Kin}$ & $40,6 \pm 0,4$ & $3,1 \pm 0,02$ & $7,7 \pm 0,9$ & $4,2 \pm 3$ & $65,6 \pm 11$ & $269 \pm 4$ \\
$+\mathrm{CA}$ & & & & & & \\
\hline
\end{tabular}




\begin{tabular}{|c|c|c|}
\hline TABEL 8 & \multicolumn{2}{|c|}{$\begin{array}{l}\text { Invloed van } \mathrm{O}_{2} \text { plus kinetien en chloor- } \\
\text { amfenikol op die inkorporering van } \\
{\left[{ }^{35} \mathrm{~S}\right]-\text { metionien in mitochondriale }} \\
\text { proteiene van Great Lakes } 659 \text {-slaai- } \\
\text { saad wat by } 25{ }^{\circ} \mathrm{C} \text { en } 36{ }^{\circ} \mathrm{C} \text { vir } 10 \mathrm{~h} \\
\text { geïmbibeer is. Konsentrasies van kine- } \\
\text { tien (Kin), } \mathrm{O}_{2} \text { en chlooramfenikol (CA) } \\
\text { soos in tabel } 1\end{array}$} \\
\hline \multicolumn{2}{|c|}{$\begin{array}{l}\text { Saadbehandeling } \\
10 \mathrm{~h}\end{array}$} & $\begin{array}{l}\text { Radioaktiwiteit } \\
\text { Bq } \mathrm{mg}^{-1} \text { proteien }\end{array}$ \\
\hline \multicolumn{2}{|c|}{$\begin{array}{l}25^{\circ} \mathrm{C}-\text { lug }+\mathrm{H}_{2} \mathrm{O} \\
25^{\circ} \mathrm{C}-\mathrm{lug}+\mathrm{CA} \\
36^{\circ} \mathrm{C}-\mathrm{lug}+\mathrm{H}_{2} \mathrm{O} \\
36^{\circ} \mathrm{C}-\mathrm{O}_{2}+\mathrm{Kin} \\
36^{\circ} \mathrm{C}-\mathrm{O}_{2}+\mathrm{Kin}+\mathrm{CA}\end{array}$} & $\begin{aligned} 141,68 & \pm 0,7 \\
35,09 & \pm 4 \\
83,39 & \pm 4 \\
161,17 & \pm 6 \\
24,01 & \pm 2\end{aligned}$ \\
\hline
\end{tabular}

metionien in mitochondriale proteiene is duidelik sigbaar. Dit is opvallend dat die profiel van radioaktiewe mitochondrionproteiene kwalitatief dieselfde was vir saad by $25^{\circ} \mathrm{C}$ (water) en $36^{\circ} \mathrm{C}\left(\mathrm{O}_{2}+\right.$ kinetien). Die watergeïmbibeerde saad by $36^{\circ} \mathrm{C}$ se radioaktiewe mito-chondrionproteienprofiel was egter kwalitatief anders. Groot verskille tussen die profiel van laasgenoemde en die mitochondrions van die $36^{\circ} \mathrm{C} \mathrm{O}_{2}+$ kinetienbehandeling word met pyltjies aangetoon.

\section{BESPREKING}

Tot redelik onlangs was die doeltreffendste behandeling om termoïnhibering by slaaisaad teë te werk, 'n kombinasie van hormone en $\mathrm{CO}_{2}{ }^{5.21}$ Onlangs is aangetoon dat $\mathrm{O}_{2}$ plus kinetien 'n nog doelftreffender behandeling is om termoïnhibering by Grand Rapids-slaai ('n swartsadige kultivar) op te hef. ${ }^{3}$ In die huidige studie is hierdie bevinding ook vir die witsadige

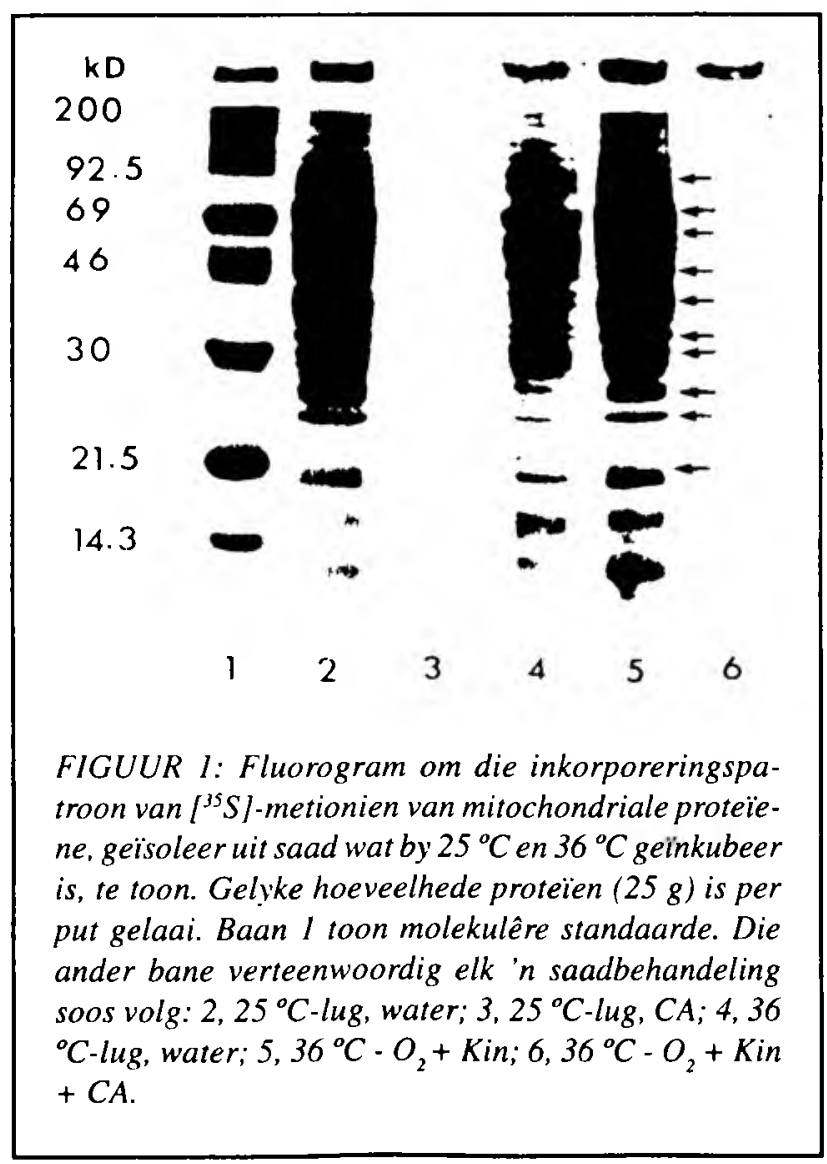

Great Lakes-kultivar, bevestig.

In 'n vorige studie ${ }^{3}$ is aangetoon dat hoë temperatuur lae vlakke van ATP in saad tot gevolg het, en dat die opheffing van termoïnhibering gepaardgaan met verhoogde ATPvlakke.

Aangesien ATP-sintese by nie-groen weefsel primêr 'n funksie van mitochondrions is, is gepostuleer dat verlaagde mitochondrionaktiwiteit moontlik ' $n$ rol by induksie van termoïnhibering speel en verhoogde mitochondrionaktiwiteit gepaardgaan met opheffing van termoïnhibering. Steun vir hierdie hipotese is met die huidige studie verkry.

Wat induksie van termoïnhibering betref, is aangetoon dat hoë temperatuur verskeie mitochondriongedrewe prosesse verlaag (heelsaadrespirasie, mitochondrionrespirasie, koppeling van mitochondrions, sekere matriksensiemaktiwiteite en inkorporering van $\left[{ }^{35} \mathrm{~S}\right]$-metionien in mitochondrionproteïene). Ten spyte van mitochondrionontkoppeling is ATP-vlakke egter nie verlaag nie. Heel waarskynlik kon verhoogde substraatvlakfosforilering hiervoor verantwoordelik wees, aangesien sade by $36^{\circ} \mathrm{C}$ (water) 'n groot toename in etanolfermentasie getoon het.

Wat opheffing van termoinhibering betref, het 'n suurstofplus kinetienbehandeling bogenoemde mitochondrionaktiwiteite tot die van $25^{\circ} \mathrm{C}$-kontrolevlakke herstel of selfs verhoog. Verder is die kwalitatiewe proteïenprofiel van gesintetiseerde mitochondrionproteiene deur hierdie behandeling volkome tot dieselfde as by $25^{\circ} \mathrm{C}$ - kontrolesade herstel.

Addisionele steun vir die rol van mitochoildrions is uit die invloed van chlooramfenikol verkry. Chlooramfenikol is 'n remmer van $70 \mathrm{~S}$ - ribosoomproteiensintese $\mathrm{e}^{21}$ en kan dus verantwoordelik wees vir remming van proteiensintese by sowel mitochondrions as plastiede. Aangesien chlooramfenikol die stimulerende invloed van $\mathrm{O}_{2}$ plus kinetien op ontkieming en mitochondrionaktiwiteite opgehef het, word aanvaar dat mitochondrionontwikkeling ter sprake is. Aspekte van die chlooramfenikolinvloed wat verdere bespreking regverdig, was die verskynsel dat hierdie remstof mitochondrionaktiwiteite en proteïensintese tot dieselfde mate by $25^{\circ} \mathrm{C}$ en $36^{\circ} \mathrm{C}$ gerem het, maar ontkieming is slegs by $36^{\circ} \mathrm{C}$ gerem. Verder is sommige mitochondrionmatrikensiem-aktiwiteite ook gerem, terwyl hulle sintese deur die nukleus, en nie mitochondrion nie, gekodeer word. Aansluitend hierby was dit ook merkwaardig dat die voorkoms van $\left[{ }^{35} \mathrm{~S}\right]-$ metioniengemerkte polipeptiede in mitochondrions tot so ' $n$ hoë mate deur chlooramfenikol gerem is.

Mitochondrion-DNA kodeer slegs vir'n klein persentasie van mitochondrions se polipeptiede. ${ }^{23}$ Die nukleus kodeer vir die oorgrote meerderheid van mitochondrionproteïene en die sintese daarvan word nie deur chlooramfenikol gerem nie. Die matriksensieme word onder andere hierby ingesluit. 'n Moontlike verklaring vir die groot remmende invloed van chlooramfenikol kan wees dat sekere membraangebonde proteiene wat by die vervoer van ander proteïene oor die membraan betrokke is, moontlik deur mitochondrion-DNA gekodeer word en dat hulle sintese deur chlooramfenikol gerem is. Dit sou kon meebring dat $\left[{ }^{35} S\right]$-metioniengemerkte proteiene wat in die sitosol vervaardig is, nie oor die mitochondrionmembraan vervoer kon word nie.

Die feit dat chlooramfenikol ontkieming slegs by $36^{\circ} \mathrm{C}$ gerem het, maar proteïensintese en mitochondrionaktiwiteite in dieselfde mate by $25^{\circ} \mathrm{C}$ en $36^{\circ} \mathrm{C}$ gerem het, dui daarop dat laer drempelwaardes van noodsaaklike metaboliete/ensieme/ proteiene by die optimum temperatuur as by 'n supraoptimale temperatuur benodig word. Indien hierdie afleiding 
korrek is, beteken dit dat vir ontkieming om by $36^{\circ} \mathrm{C}$ te kan plaasvind, daar addisionele vervaardiging van noodsaaklike selbestanddele moet plaasvind. Hierdie gedagte word gesteun deur die bevinding dat suurstof plus kinetien, wat termoïnhibering opgehef het, inderdaad ' $n$ toename in ATP. vlakke en omvang van proteiensintese hoër as wat by $25^{\circ} \mathrm{C}$ geïnkubeerde sade voorgekom het, tot gevolg gehad het. Dit was ook duidelik dat proteiensintese by termogeinhibeerde sade kwalitatief anders was as by nie-geïnhibeerde saad.

Die resultate van hierdie studie ondersteun dus die hipotese wat aanvanklik gestel is. Daar word afgelei dat die afname van sekere mitochondrionaktiwiteite, moontlik weens remming van mitochondrionontwikkeling tydens imbibering, 'n veroorsakende faktor by die induksie van termoïnhibering van slaaisaad is. Opheffing van termoinhibering blyk gekoppel te wees aan die herstel van hierdie aktiwiteite moontlik tot 'n hoër vlak as by 'n nie-remmende temperatuur.

\section{Summary}

In a previous study ${ }^{3}$ with Grand Rapids lettuce, a black seeded cultivar, a combination of $100 \% \mathrm{O}_{2}$ and kinetin $\left(10 \mathrm{mg} \mathrm{dm}^{-3}\right)$ was found to totally alleviate the induction of thermoinhibition at $38^{\circ} \mathrm{C}$. Furthermore this treatment greatly enhanced the ATP level in seeds indicating that enhanced mitochondrial activity could be causative in alleviating thermoinhibition. This hypothesis was tested in the present study in which a white seeded lettuce cultivar, Great Lakes 659 was used.

Seeds were imbibed at $25^{\circ} \mathrm{C}$ and $36^{\circ} \mathrm{C}$ in the light. The effect of a combination of hormones, $\mathrm{CO}_{2}(10 \%)$ and $\mathrm{O}_{2}$ $(100 \%)$ on germination as well as the effect of chloramphenicol an inhibitor of $70 \mathrm{~S}$ ribosome protein synthesis was tested. Whole seed respiration, ethanolic fermentation and ATP levels, mitochondrial respiration, ADP:0 ratios, matrix enzyme activities and incorporation of $\left[{ }^{35} \mathrm{~S}\right]$-methionine in mitochondrial polypeptides was determined in seeds from selected treatments.

In air, germination was inhibited at $36^{\circ} \mathrm{C}$ (thermoinhibition). Thermoinhibition was relieved to some extent by a combination of hormones and $\mathrm{CO}_{2}$ in air, neither factor alone being effective. The most efficient treatment to alleviate thermoinhibition was a combination of $100 \% \mathrm{O}_{2}$ and kinetin $\left(10 \mathrm{mg} \mathrm{dm}^{-3}\right)$, followed by a combination of $\mathrm{O}_{2}$ and ethylene.

Chloramphenicol nullified the beneficial effect of all treatments which in its absence, relieved thermoinhibition. At $25{ }^{\circ} \mathrm{C}$ in air chloramphenicol retarded germination during the first $24 \mathrm{~h}$ but after $48 \mathrm{~h}$ did not severely inhibit germination. However, as the temperature was increased chloramphenicol increasingly inhibited germination.

Pregermination respiratory capacity of whole seeds and isolated mitochondria was reduced and mitochondria were uncoupled in thermoinhibited seeds. Both detrimental effects were alleviated by $\mathrm{O}_{2}$ plus kinetin. This effect was reversed by chloramphenicol. Activities of $\alpha$-ketoglutaric acid dehydrogenase, malate dehydrogenase, pyruvate dehydrogenase and malic enzyme were reduced in thermoinhibited seeds. Activities of these enzymes, with the exception of pyruvate dehydrogenase were restored by $\mathrm{O}_{2}$ plus kinetin.

Incorporation of $\left[{ }^{35} \mathrm{~S}\right]$-methionine in mitochondrial polypeptides was markedly reduced in thermoinhibited seeds. Oxygen plus kinetin treatment reversed this effect resulting in a higher level of protein synthesis than in $25^{\circ} \mathrm{C}$ water controls. The profile of $\left[{ }^{35} \mathrm{~S}\right]$-methionine labelled mitochondrial polypeptides from thermoinhibited seeds differed qualitatively from that of seeds imbibed at $25^{\circ} \mathrm{C}$ and seeds treated with $\mathrm{O}_{2}$ plus kinetin at $36^{\prime \prime} \mathrm{C}$. The $\left[{ }^{35} \mathrm{~S}\right]$-methionine labelled protein profiles of seeds from the latter two treatments were identical.

The results of this study support the hypothesis that induction of thermoinhibition is related to reduction in mitochondrial function and that stimulation of mitochondrial activity/development could be causative in the alleviation of thermoinhibition.

\section{DANKBETUIGING}

Finansiële steun vir hierdie werk is vanaf die Universiteit van die Oranje-Vrystaat en die Stigting vir Navorsingsontwikkeling ontvang.

\section{LITERATUURVERWYSINGS}

I. Kristie, D.N., Bassi, P.K. \& Spencer, M.S. (1981). Factors affecting the induction of secondary dormancy in lettuce, Plant Physiol, 67, 1224-1229.

2. Thompson, D.A., Cox, S.A. \& Sanderson, R.H. (1979). Characterization of germination response to temperature of lettuce (Lactuca sativa L.) achenes, Annals of Bolany, 43, 319-334.

3. Small, J.G.C., Schultz, C. \& Cronje, E. (1993). Relief of thermoinhibition in Grand Rapids lettuce seeds by oxygen plus kinetin and their effects on respiration, content of ethanol and ATP and synthesis of ethylene, Seed Sci. Res., 3, 129-135.

4. Vidaver, W. \& Hsiao, A.l. (1975). Secondary dormancy in lightsensitive lettuce seeds incubated anaerobically or at elevated temperature, Can. I. Bot., 53, 2557-2560

5. Saini, H.S., Consolacion, E.D., Bassi, P.K. \& Spencer, M.S. (1986). Requirement for ethylene synthesis and action during relief of thermoinhibition of lettuce seed germination by combinations of gibberellic acid, kinetin and carbon dioxide, Plant Physiol., 81, 950953.

6. Raymond, P. \& Pradet, A. (1980). Stabilization of adenine nucleotide ratios at various values by an oxygen limitation of respiration in germinating lettuce (Lacruca sariva) seeds, Biochem. J., 190, 39 44.

7. Small, J.G.C., Potgieter, G.P. \& Botha, F.C. (1989). Anoxic seed germination of Erythrina caffra: Ethanol fermentation and response to metabolic inhibitors, J. Exp. Bot., 40, 375-381.

8. Morohashi, Y., Seto, T. \& Matsushima, H. (1991). Appearance of alternative respiration in cucumber cotyledon mitochondria after treatment with cycloheximide, Physiol. Plant., 83, 640-646.

9. Neuburger, M. (1985). Preparation of plant mitochondria, criteria for assessment of mitochondrial integrity and purity, survival in vitro, In Encyclopedia of plant physiology. Douce, R. \& Day, D. A. eds. (Springer-Verlag, Berlin), pp. 7-24.

10. Dry, 1.B. \& Wiskich, J.T. (1987). 2-Oxoglutarate dehydrogenase and pyruvate dehydrogenase activities in plant mitochondria: Interaction via a common coenzyme A pool. Arch. Biochem. Biophy's., 257, 92-99

11. Rustin, P. Moreau, F. \& Lance, C. (1980). Malate Oxidation in plant mitochondria via malic enzyme and the cyanide-insensitive electron transport pathway, Plant Physiol., 66, 457-462.

12. Cooper, T.G. (1977). The wools of biochemistry (Wiley, New York), pp. $351-352$.

13. Cook, N.D. \& Cammack, R. (1985). Properties of a soluble rotenone insensitive NADH dehydrogenase released from Arum maculatum mitochondrial membranes by sonication. Biochim. Biophys. Acta, 827, 30-35.

14. Van der Plas, L.H.W., Jobse, P.A. \& Verleur, J.D. (1976). Cytochrome $C$ dependent, antimycin-A resistant respiration in mitochondria from potato tuber (Solanum tuberosum L.). Influence of wounding and storage time on outer membrane NADHcytochrome-c-reductase, Biochim. Biophys. Acta, 430, 1-12.

15. Bradford, M.M. (1977). A rapid and sensitive method for the quantitation of microgram quantities of protein utilizing the princi- 
ple of protein-dye binding, Anal. Biochem., 72, 248-254.

16. Spencer, D., Higgins, T.J.V., Bullou, S.C. \& Davey, R.A. (1980) Pulse-labeling studies on protein synthesis in developing pea seeds and evidence of a precursor form of legumin small subunit, Plant. Physiol., 66, 510-515.

17. Botha, F.C., \& Small, J.G.C. (1985). Effect of water stress on the carbohydrate metabolism of Citrullus lanatus seeds during germination, Plant Physiol., 77, 79-82.

18. Laemmli, U.K. (1970). Cleavage of structural proteins during the assembly of the head of bacteriophage T4, Nature, 227, 680-685.

19. Fish. I.E. \& Jagendorf, A.T. (1982). High rates of protein synthesis by isolated chloroplasts, Plant Physiol., 70, 1107-1114
20. Sotelo, J.N. \& Ho, T-HD. (1987). Absence of heat shock protein synthesis in isolated mitochondria and plastids from maize, J. Biol. Chem., 262, 12288-12292.

21. Keys, R.D., Smith, O.E., Kumamoto, J. \& Lyon, J.L. (1975). Effect of gibberellic acid, kinetin and ethylene plus carbon dioxide on the thermodormancy of lettuce seed (Lactuca sativa L. cv. Mesa 659), Plant Physiol., 56, 826-829.

22. Schuster, W. \& Brennicke, A. (1994). The plant mitochondrial genome: Physical Structure, information content, RNA editing, and gene migration to the nucleus, Annu. Rev. Plant Physiol. Plant Mol. Biol., 45, 61-78. 